\title{
Extrapolation of imidacloprid toxicity between soils by exposing Folsomia candida in soil pore water
}

\author{
Afolarin O. Ogungbemi ${ }^{1,2,3} \cdot$ Cornelis A. M. van Gestel (1)
}

Accepted: 9 July 2018 / Published online: 30 July 2018

(c) The Author(s) 2018

\begin{abstract}
Soil properties like organic matter $(\mathrm{OM})$ content show great variation, making it hard to predict the fate and effects of a chemical in different soils. We therefore addressed the question: can we remove the complexity of the soil matrix and yet accurately predict soil toxicity from porewater exposures? Folsomia candida was exposed to imidacloprid in natural (LUFA $2.2[4.02 \% \mathrm{OM}]$, Grassland $[12.6 \% \mathrm{OM}]$ ) and artificial soils (OECD $5[6.61 \% \mathrm{OM}]$, OECD $10[10.8 \% \mathrm{OM}]$ ), in pore water extracted from spiked LUFA 2.2 soil and in water. Toxicity decreased with increasing OM content except for Grassland soil, which had the highest OM content but the lowest clay content, suggesting a role of clay minerals in the binding of imidacloprid. Distribution coefficients for imidacloprid based on toxicity (Toxicity- $K_{\mathrm{d}}$ ) were derived by comparing effect concentrations in LUFA 2.2 soil and in water. Using these Toxicity- $K_{\mathrm{d}} \mathrm{s}$ to recalculate soil $\mathrm{LC}_{50} \mathrm{~s} / \mathrm{EC}_{50} \mathrm{~s}$ to porewater concentrations, the differences in $\mathrm{LC}_{50} / \mathrm{EC}_{50} \mathrm{~S}$ almost disappeared. The recalculated porewater $\mathrm{LC}_{50} \mathrm{~s}$ did not differ by more than a factor of $0.55-1.43$ from the $\mathrm{LC}_{50}$ obtained upon water exposure. This similarity suggests that the toxicity in the soil is dependent on porewater concentrations and can be obtained from water exposure. The porewater test and the corresponding "pore-water extrapolation concept" developed in this study may be used to predict the toxicity of chemicals in the soil and extrapolate among different soils.
\end{abstract}

Keywords Collembola $\cdot$ Imidacloprid $\cdot$ Organic matter $\cdot$ Bioavailability $\cdot$ Soil ecotoxicology $\cdot$ Hazard/risk assessment

\section{Introduction}

In soil ecotoxicology, it is standard practice to expose soil organisms to chemicals in soil media, and the effect endpoint is usually estimated based on the concentration of the chemical in the soil. In the past, some limitations have been identified with this practice. First, exposure of organisms to

Electronic supplementary material The online version of this article (https://doi.org/10.1007/s10646-018-1965-x) contains supplementary material, which is available to authorized users.

$\square$ Cornelis A. M. van Gestel

kees.van.gestel@vu.nl

1 Department of Ecological Science, Faculty of Science, Vrije Universiteit, Amsterdam, The Netherlands

2 Institute for Environmental Sciences, Universität Koblenz-Landau, Landau, Germany

3 Present address: Department of Bioanalytical Ecotoxicology, UFZ-Helmholtz Centre for Environmental Research, Leipzig, Germany the same chemical in different soils results in different effect concentrations (Van Gestel and Van Dis 1988; Dean-Ross 1983). Therefore, it is not possible to compare results of toxicity tests and this led to excessive testing of the same chemicals in different soils. Physicochemical properties such as organic matter $(\mathrm{OM})$ content, clay content and $\mathrm{pH}$ are known to influence the fate and bioavailability of a chemical in the soil (Bonmatin et al. 2015). Hence, the fraction of chemical available for uptake by organisms varies, leading to different effect concentrations in different soils (Van Gestel 2012). This limitation was circumvented by developing standard soil media such as the OECD artificial soil (OECD 1984) and LUFA soils (LUFA Speyer Germany), which may ensure comparability and reproducibility of toxicity data. The OECD soil is utilized for standard tests such as the Earthworm acute and reproduction toxicity tests (OECD 2004) and the Collembolan reproduction toxicity test (OECD 2009). However, due to a better representation of the natural ecosystem, the LUFA soils are gaining wider acceptance.

Second, soft bodied and in-soil dwelling organisms such as earthworms and springtails are known to take up 
chemicals via the soil pore water (Belfroid et al. 1996; Fountain and Hopkin 2005). Hence, chemicals dissolved in the pore water are assumed to be highly bioavailable compared to those adsorbed to the soil. Although estimating the effect of chemicals on these organisms based on total soil concentrations is widely accepted, such estimates are quite unrepresentative of the actual concentrations causing the effect (Bradham et al. 2006). Appropriate knowledge of exposure levels is required for a proper estimate of ecotoxicological effects (Van Gestel and Weeks 2004). Of course, the internal concentration of a chemical in an organism would provide a better estimate of effects; however, measuring such concentrations is time and resource demanding and therefore unsuitable for routine ecotoxicological tests (Escher and Hermens 2004). Thus, it seems logical to advocate the use of porewater concentrations in soil ecotoxicological tests. For example, Van Gestel and Ma (1988) exposed earthworms to chlorophenols in four soils and recalculated the soil $\mathrm{LC}_{50}$ to porewater concentrations. They found a factor of 4.4-12.8 difference for soil $\mathrm{LC}_{50} \mathrm{~s}$, which significantly reduced to a factor of 1.2-2.4 when $\mathrm{LC}_{50} \mathrm{~s}$ were based on porewater concentrations. Consequently, they postulated the porewater hypothesis which states that the concentration of a chemical in an organism is considered to be related to the porewater concentration which in turn depends on the sorption behavior of the chemical in the soil.

The porewater hypothesis has been confirmed by other studies that reported greatly reduced variation between soils when employing porewater concentrations (Ronday et al. 1997; Martikainen and Krogh 1999; Waalewijn-Kool et al. 2014). The validity of the porewater hypothesis motivates the extrapolation of toxicity data from one soil to another as well as predicting soil toxicity from water exposure. It therefore is surprising that the simplification offered by this hypothesis has not been utilized to a greater extent in soil ecotoxicology. However, some exceptions exist for the implementation of this hypothesis (Van Gestel 1997). First, highly lipophilic chemicals are expected to strongly adsorb to the soil matrix leading to increased importance of oral uptake. Belfroid (1994) found that the contribution of oral uptake increased when earthworms were exposed to highly lipophilic chemicals in soils with high organic matter content. Similarly, Jager et al. (2003) showed the importance of oral uptake after exposing earthworms to hydrophobic chemicals while preventing them from feeding. Both authors concluded that the contribution of the oral uptake route is less than a factor of 2 and the porewater hypothesis could still be useful in risk assessment. Second, for metals, sorption is governed by other factors including $\mathrm{pH}$ and clay content. Therefore an alternative hypothesis was proposed, which relates toxicity to free metal ion activity in the soil solution (Van Gestel 1997). This hypothesis has been elaborated in the Biotic Ligand Model (see e.g., Ardestani et al. 2014).

Ronday and Houx (1996) assessed the suitability of exposing seven species of soil organisms in simulated pore water and Folsomia candida was considered to be most suitable and sensitive. Hence, $F$. candida was chosen as the organism for the present study because of its vulnerability to soil contamination via soil pore water, which makes it a good soil quality indicator (Filser et al. 2014). Springtails are equipped with a ventral tube which enables them to exchange water and oxygen with the environment (Lock and Janssen 2003; Fountain and Hopkin 2005). Their hydrophobic ventral tube and ability to walk on water make F. candida suitable for aquatic toxicity tests (Houx et al. 1996). In the present study, we aimed at answering the following questions: (1) To what extent do differences in soil organic matter content influence the toxicity of imidacloprid to $F$. candida? (2) Can we remove the complexity of the soil matrix and yet accurately predict soil toxicity from porewater exposures? Based on these questions, we hypothesized that the toxicity obtained on exposure to organic chemicals in water would equal the toxicity obtained in pore water extracted from spiked soil, and this should correlate with the toxicity obtained in the soil via factoring in organic matter content. In view of this, we exposed $F$. candida in soil, water and pore water extracted from spiked soil.

\section{Materials and methods}

\section{Test organism}

Folsomia candida (Denmark strain, Vrije Universiteit, Amsterdam) were cultured in plastic boxes with a moist bottom made of a mixture of plaster of Paris and charcoal at a ratio 10:1. Animals were fed dried baker's yeast (Instant yeast from Algist Bruggeman N.V, Ghent, Belgium) and cultures were maintained at $20^{\circ} \mathrm{C}$ and $12 \mathrm{~h}$ light $/ 12 \mathrm{~h}$ dark cycle in a climate chamber. Adult $F$. candida were incubated in culture boxes and removed after 2 days of egg laying. Juveniles emerged after 10 days and the toxicity tests were initiated with 10-12 day old animals.

\section{Soil spiking with imidacloprid}

This study used two OECD artificial soils, LUFA 2.2 standard soil (LUFA-Speyer 2.2 Sp 2121, Germany) and a Grassland soil collected in the Netherlands (Natal-da-Luz et al. 2012). The first artificial soil was prepared by mixing $70 \%$ silver sand, $20 \%$ kaolin clay and $10 \%$ peat, hereafter referred to as OECD 10. The second artificial soil was made up of $75 \%$ silver sand, $20 \%$ kaolin clay and 5\% peat, hereafter referred to as OECD 5. Both artificial soils were 
prepared according to OECD (2009). LUFA 2.2 soil (7.7\% clay, $4.02 \% \mathrm{OM}$ ) was purchased and dried in the oven at 50 ${ }^{\circ} \mathrm{C}$ prior to use. Grassland soil ( $4.8 \%$ clay, $\left.12.6 \% \mathrm{OM}\right)$ was collected in 2012 from a field site located in the Netherlands and has since been stored in dry form in the laboratory.

The Imidacloprid powder ( $98 \%$ purity) used for the toxicity tests was obtained from Bayer Crop Science, Germany in 2014. Imidacloprid has a low vapor pressure and Henry's constant of $1.0 \times 10^{-7} \mathrm{~mm} \mathrm{Hg}$ and $6.5 \times 10^{-11} \mathrm{~atm}$ $\mathrm{m}^{3} / \mathrm{mole}$, respectively, indicating low volatility. It has a relatively high water solubility $(0.51 \mathrm{~g} / \mathrm{L})$ and low octanolwater partition coefficient $[\mathrm{Log}$ Kow $=0.57]$ (Fossen 2006). Solutions of imidacloprid were prepared in deionized water to give concentrations of $45.5,36.6,45.5$ and $55.6 \mathrm{mg} / \mathrm{L}$ for the stocks to spike LUFA2.2, Grassland, OECD 10 and OECD 5 soil, respectively. The solutions were serially diluted by a factor of 3 and spiked into the test soils to obtain nominal soil concentrations of $0.03,0.11$, $0.33,1.11,3.33$ and $10 \mathrm{mg} / \mathrm{kg}$ dry soil. The concentrations in the stock solutions and the dilutions were undertaken in such a way that the obtained volume was also sufficient to moisten the soil to the desired level. Control soil was spiked with deionized water only. LUFA 2.2, OECD 5 and OECD 10 soils were moistened to $50 \%$ of the water holding capacity (WHC) while Grassland soil was moistened to $38 \%$ of the WHC. The spiked soils were allowed to stand overnight for appropriate equilibration of the chemical.

\section{Soil toxicity test}

The effect of imidacloprid on the survival and reproduction of $F$. candida was investigated according to OECD (2009). Ten (10-12 day old) juvenile $F$. candida were exposed in $100 \mathrm{~mL}$ glass jars containing $30 \mathrm{~g}$ of the test soil spiked with varying concentrations of imidacloprid $(0.03,0.11$, $0.33,1.11,3.33$ and $10 \mathrm{mg} / \mathrm{kg}$ dry soil) and a control. Five replicates per concentration were prepared and a few grains of dried baker's yeast were added for food. The glass jars were aerated and remoistened weekly to replenish air and water, respectively. According to Crouau and Cazes (2003), variability of the reproduction test can be reduced by increasing the duration of the test. Therefore, survival and reproduction were assessed after 14 (for LUFA 2.2 only) and 33 days (for the four test soils) of incubation by extracting the animals from the soil by means of flotation (OECD 2009). Photographs were taken to manually count the number of juveniles and adults with image $\mathbf{J}$ software.

\section{Porewater toxicity tests}

After overnight equilibration of LUFA 2.2 soil spiked as described above, soil samples were collected and centrifuged with a relative centrifugal force of $2000 \times g$ over a
Schleicher and Schuell $0.45 \mu \mathrm{m}$ membrane filter placed in between two filter papers in a centrifuge (MSE FALCON 6/ $300)$. The resulting filtrate was collected and utilized as the porewater exposure media.

To enable comparison of exposures in the porewater media with effects following exposure to water media with known concentrations, water media were prepared by dissolving an appropriate amount of imidacloprid in deionized water to give a concentration of $30 \mathrm{mg} / \mathrm{L}$. This solution was further diluted with deionized water to give nominal concentrations of $0.03,0.11,0.33,1.11,3.33,10$ and $30 \mathrm{mg} / \mathrm{L}$, and including a water control.

F. candida (10-12 day old) were simultaneously exposed to imidacloprid in pore water extracted from spiked LUFA 2.2 soil $\left(\mathrm{PW}_{\mathrm{e}}\right)$ and in water for 33 days, following a modification of the test method reported by Houx et al. (1996). One $\mathrm{mL}$ of the respective solution was transferred into small glass vials (volume of $2 \mathrm{ml}$ and dimensions of $12 \times 35 \mathrm{~mm}$ ) arranged in a multi-well column. Four $F$. candida were added to the solution in each vial and the glass vials were loosely closed. Five replicates per treatment were prepared and food was not added. Assessments were done daily by recording the number of active, affected, moribund or dead animals. Animals were judged dead if immobile after disturbing with a wave of air. Additionally, behavioral effects were monitored daily by categorizing the activity of the organisms. The effects were categorized according to Houx et al. (1996) as: (1) hyperactivity and escape from the water surface to the glass wall; (2) vigorous shaking of the body; (3) spring-forks folded out so that jumping was impossible; (4) standing upright or lying sideways with vigorous flexand-stretch movements of the body and energetic movements of legs and antennae; (5) standing or lying with trembling legs and antennae; (6) droplets of clear colorless fluid emerging from all parts of the body; (7) standing or lying with hardly noticeable shivering in legs and antennae; (8) dead animals were fully stretched out, with their fork folded out and their legs swollen. These behavioral effects were aggregated into four groups during the assessments: Active (effect 1), Affected (effects 2, 3 and 4), Moribund (effects 5, 6 and 7) and Dead (effect 8).

\section{Data analysis}

Results were obtained as numbers of surviving adults/juveniles and a dose-response curve was fitted to the data using a log-logistic or a Weibull model (Ritz and Streibig 2005). The lethal concentration at which $50 \%$ of the adults were killed $\left(\mathrm{LC}_{50}\right)$ was estimated from the dose-response curve. The best fitting curve was selected based on Akaike information criteria. Additionally, results were obtained as number of active and affected adults for the soil, porewater and water tests. In these cases, lethality and moribundity 
Table 1 Properties of four different soils and the corresponding $\mathrm{LC}_{50} / \mathrm{EC}_{50}$ values for the toxicity of imidacloprid to Folsomia candida exposed for 33 days in these soils

\begin{tabular}{lllllll}
\hline Soil & $\mathrm{pH} \mathrm{CaCl}_{2}$ & $\begin{array}{l}\mathrm{OM} \text { content } \\
(\%)\end{array}$ & $\mathrm{WHC}^{\mathrm{c}}(\%)$ & $\begin{array}{l}\text { Clay content } \\
(\%)\end{array}$ & $\begin{array}{l}\mathrm{LC}_{50}(\mathrm{mg} / \mathrm{kg} \text { dry } \\
\text { soil })\end{array}$ & $\begin{array}{l}\mathrm{EC}_{50}(\mathrm{mg} / \mathrm{kg} \text { dry } \\
\text { soil })\end{array}$ \\
\hline LUFA 2.2 & 6.26 & $4.02 \pm 0.05$ & $44^{\mathrm{a}}$ & $7.7^{\mathrm{a}}$ & $0.31(0.22-0.39)$ & $0.14(0.11-0.17)$ \\
OECD 5 & 6.05 & $6.61 \pm 0.09$ & $32^{\mathrm{c}}$ & 20 & $0.98(0.63-1.34)$ & $0.63(0.34-0.92)$ \\
OECD 10 & 5.92 & $10.9 \pm 0.17$ & $40^{\mathrm{c}}$ & 20 & $1.63(0.96-2.30)$ & $2.07(1.42-2.72)$ \\
Grassland & 6.84 & $12.6 \pm 0.79$ & $73^{\mathrm{b}}$ & $4.8^{\mathrm{b}}$ & $0.73(0.35-1.11)$ & $1.04(0.80-1.27)$ \\
\hline
\end{tabular}

$\mathrm{LC}_{50}$, effects on survival; $\mathrm{EC}_{50}$, effects on reproduction; $O M$, organic matter $( \pm \mathrm{SD}, n=3)$ determined as loss on ignition at $500{ }^{\circ} \mathrm{C}$; $W H C$, water-holding capacity; $\mathrm{LC}_{50} / \mathrm{EC}_{50}$ ( $95 \%$ confidence interval in parentheses)

${ }^{a}$ Data obtained from LUFA Speyer analyses data sheet

${ }^{\mathrm{b}}$ Data from Natal-da-luz et al. (2012)

${ }^{\mathrm{c}} \mathrm{WHC}$ determined as moisture content after saturation with water were combined as the end point $\left(\mathrm{LMC}_{50}\right)$. The concentration of imidacloprid in the $\mathrm{PW}_{\mathrm{e}}$ could not be determined because of the large volume of the pore water that was required for the analysis. Therefore, porewater effect concentrations had to be derived indirectly from water effect concentrations by correlating $\mathrm{PW}_{\mathrm{e}} \mathrm{LMC}_{50}\left(\mathrm{mg} / \mathrm{kg}\right.$ soil) against water $\mathrm{LMC}_{50}$ $(\mathrm{mg} / \mathrm{L})$. All statistical analyses related to effect concentrations were implemented using the statistical software environment $\mathrm{R}$ for Windows (RStudio Team 2016).

To estimate porewater effect concentrations for the other soils, soil $\mathrm{LC}_{50} / \mathrm{EC}_{50} \mathrm{~s}$ were recalculated to give modelled porewater $\left(\mathrm{PW}_{\mathrm{m}}\right) \quad \mathrm{LC}_{50} / \mathrm{EC}_{50} \mathrm{~s}$. This recalculation was facilitated by determining the binding of imidacloprid to soil. For that purpose, the distribution coefficient $\left(K_{\mathrm{d}}\right)$ based on toxicity (Toxicity- $K_{\mathrm{d}}$ ) was estimated for imidacloprid by dividing the soil $\mathrm{LMC}_{50}$ with the water $\mathrm{LMC}_{50}$ (Eq. 1).

LUFA 2.2 Toxicity $-K_{d}=\frac{\text { soil } L M C_{50}}{\text { water } L M C_{50}}$

An organic carbon partition coefficient $\left(K_{\mathrm{oc}}\right)$ for imidacloprid in LUFA 2.2 soil was estimated by dividing the Toxicity- $K_{\mathrm{d}}$ with the fraction of organic carbon $\left(\mathrm{F}_{\mathrm{oc}}\right)$ in the soil (Eq. 2).

$K_{o c}=\frac{\text { LUFA 2.2 Toxicity }-K_{d}}{\text { LUFA } 2.2 F_{o c}}$

Imidacloprid is assumed to mainly bind to $\mathrm{OM}$ and its $K_{\text {oc }}$ was found to remain similar in different soils (Liu et al. 2006). We then used the LUFA $2.2 K_{\mathrm{oc}}$ based on toxicity as a normalizing factor to estimate Toxicity- $K_{\mathrm{d}}$ values for the other soils (Eq. 3).

Toxicity $-K_{d}=K_{o c} \times F_{o c}$

The estimated Toxicity- $K_{\mathrm{d}} \mathrm{s}$ were used to recalculate soil $\mathrm{LC}_{50} / \mathrm{EC}_{50} \mathrm{~s}$ in $\mathrm{mg} / \mathrm{kg}$ dry soil into $\mathrm{PW}_{\mathrm{m}} \mathrm{LC}_{50} / \mathrm{EC}_{50} \mathrm{~s}$ in $\mathrm{mg} / \mathrm{L}$ for the four different test soils (Eq. 4).

$L C_{50} m g / L=\frac{L C_{50} m g / k g}{\text { Toxicity }-K_{d}}$

\section{Results}

\section{Control performance}

The toxicity tests in the four different soils were considered valid according to the validity criteria stipulated by OECD (2009). Mean adult mortality in the controls did not exceed $20 \%$ with values of 16, 4, 12 and $8 \%$ for LUFA 2.2, OECD 5, OECD 10 and Grassland soils, respectively. The mean number of juveniles in the control vessels met the required minimum of 100 with average values of 612, 694, 564 and 394, respectively. The coefficients of variation for the juvenile numbers in replicate controls were below $30 \%$ with values of 17.8, 12.4, 26.1 and $19.7 \%$ for LUFA 2.2, OECD 5, OECD 10 and Grassland soils, respectively. Cumulative control mortalities in the porewater and water tests were 5 and $0 \%$, respectively, hence the tests were considered valid. Even though animals were not fed in porewater and water tests, they showed good fitness in the controls for the duration of the test. However, activity of the animals was lower in porewater controls than in water controls.

\section{Toxicity estimations in soil, water and pore water}

Imidacloprid affected both adult survival and reproduction of $F$. candida in a dose-related manner (Figure S1-S4, Supporting Information). The estimated $\mathrm{LC}_{50}$ and $\mathrm{EC}_{50}$ values are reported in Table 1 . Toxicity of imidacloprid to $F$. candida increased with decreasing OM content except for Grassland soil which had the highest OM content. Imidacloprid was most toxic in LUFA 2.2 which is the soil with the lowest $\mathrm{OM}$ content $\left(\mathrm{LC}_{50}=0.31, \mathrm{EC}_{50}=0.14 \mathrm{mg} /\right.$ $\mathrm{kg}$ dry soil $)$ and least toxic in OECD $10\left(\mathrm{LC}_{50}=1.63, \mathrm{EC}_{50}\right.$ $=2.07 \mathrm{mg} / \mathrm{kg}$ dry soil). The relationship between effect concentrations and OM content (Fig. 1) without Grassland soil resulted in Pearson correlation coefficients (r) of 0.98 and 0.99 for $\mathrm{LC}_{50}$ and $\mathrm{EC}_{50}$, respectively.

For the porewater and water tests, the animals did not quickly experience death but did show behavioral effects. 


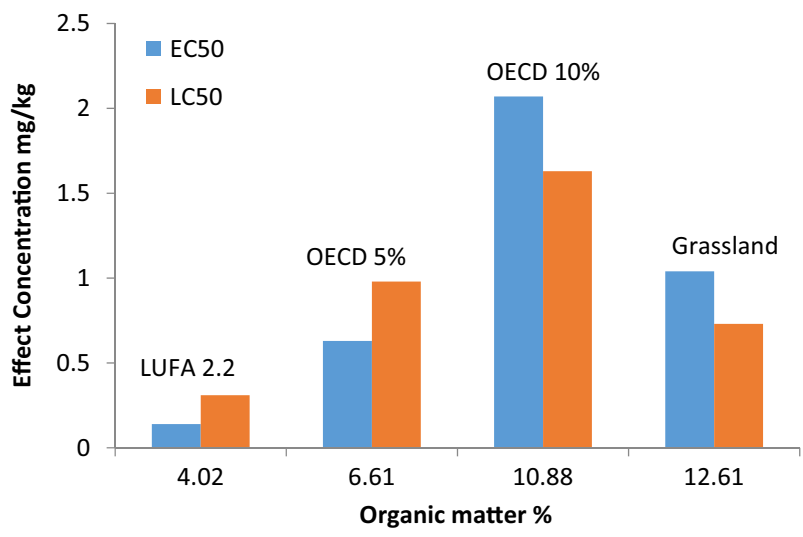

Fig. 1 Bar chart showing the relationship between effect concentrations $\left(\mathrm{LC}_{50}\right.$ and $\mathrm{EC}_{50}$ ) for the toxicity of imidacloprid to Folsomia candida and the organic matter content of the four test soils

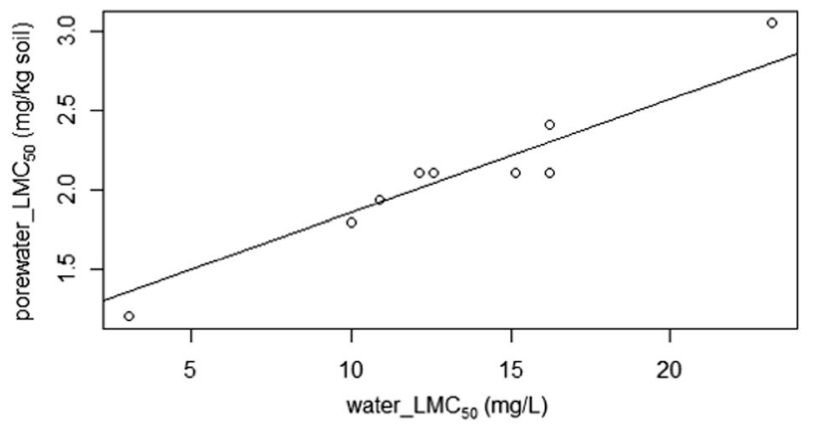

Fig. 2 Regression curve $\left(\mathrm{R}^{2}=0.89, \quad \mathrm{y}=0.085 \mathrm{x}+0.98\right)$ relating $\mathrm{LMC}_{50}$ s for the toxicity of imidacloprid to Folsomia candida exposed to pore water extracted from freshly spiked LUFA 2.2 soil to $\mathrm{LMC}_{50} \mathrm{~S}$ for exposure in water. $\mathrm{LMC}_{50} \mathrm{~s}$ in pore water are in $\mathrm{mg} / \mathrm{kg}$ dry soil, those in water in $\mathrm{mg} / \mathrm{L}$. Data points show $\mathrm{LMC}_{50} \mathrm{~s}$ recorded at different times of exposure
Table 2 Toxicity- $K_{\mathrm{d}}$ values describing the sorption of imidacloprid in LUFA 2.2 soil estimated from the $\mathrm{LMC}_{50} \mathrm{~s}$ for lethal and moribund effects on Folsomia candida exposed for 14 and 33 days in soil, in water, and in pore water extracted from the LUFA 2.2 soil

Generally, there was a progression of these behavioral effects (Active-Affected-Moribund-Dead) during the course of exposure until death. The Lethal-moribund effect concentrations $\left(\mathrm{LMC}_{50}\right)$ for porewater and water tests are reported in Table S1 in the Supporting Information and the $\mathrm{LMC}_{50} \mathrm{~S}$ estimated for soil toxicity are in Table 2 . Since concentration of imidacloprid in the pore water extracted from spiked LUFA 2.2 soil $\left(\mathrm{PW}_{\mathrm{e}}\right)$ was not measured, $\mathrm{PW}_{\mathrm{e}}$ $\mathrm{LMC}_{50} \mathrm{~s}$ in $\mathrm{mg} / \mathrm{kg}$ dry soil were converted to values in $\mathrm{mg} / \mathrm{L}$ by comparison with the water $\mathrm{LMC}_{50} \mathrm{~s}$ in $\mathrm{mg} / \mathrm{L}$. This comparison resulted in a regression with an $\mathrm{R}^{2}$ of $0.89, \mathrm{Y}=$ $0.085 x+0.98$ (Fig. 2). This conversion was based on the assumption that the response of $F$. candida to imidacloprid in $\mathrm{PW}_{\mathrm{e}}$ and water should be similar since sorption to dissolved organic matter may not be influential (Houx and Aben 1993). The estimated $\mathrm{LMC}_{50} \mathrm{~s}$ for $\mathrm{PW}_{\mathrm{e}}$ were very similar to the water $\mathrm{LMC}_{50} \mathrm{~S}$ except for exposure days 2 and 3 , where the $\mathrm{LMC}_{50} \mathrm{~s}$ were about 3 fold higher for $\mathrm{PW}_{\mathrm{e}}$ than for water exposure. Figure 3 shows decrease of the $\mathrm{LMC}_{50} \mathrm{~S}$ over time.

The distribution coefficient for the binding of imidacloprid to LUFA 2.2 soil $\left(\mathrm{F}_{\mathrm{oc}}=0.023\right)$ estimated from the $K_{\mathrm{ow}}$ of imidacloprid (3.7) is $0.085 \mathrm{~L} / \mathrm{kg}$. The toxicity-based distribution coefficients (Toxicity- $K_{\mathrm{d}}$ ) estimated from the $\mathrm{LMC}_{50} \mathrm{~s}$ for the toxicity to $F$. candida in soil and water after 14 and 33 days of exposure (Table 2) were similar at $0.03 \mathrm{~L} / \mathrm{kg}$ and $0.05 \mathrm{~L} / \mathrm{kg}$, respectively. Using the Toxicity$K_{\mathrm{d}}$ for day 33, an organic carbon partition coefficient

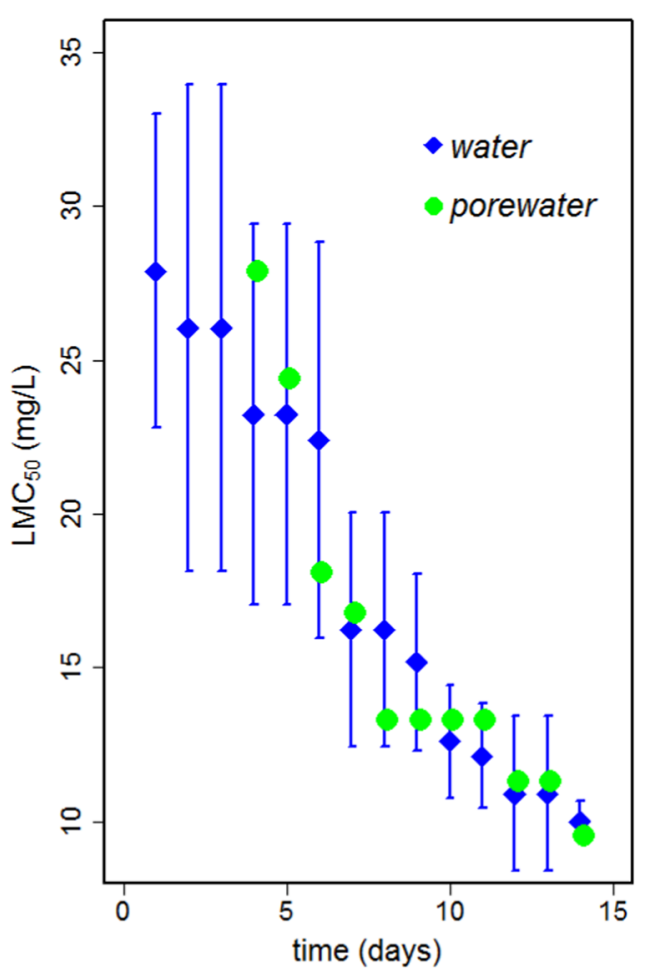

Fig. 3 Plot of $\mathrm{LMC}_{50} \mathrm{~s}$ against exposure time for the toxicity of imidacloprid to Folsomia candida exposed in water or in pore water extracted from freshly spiked LUFA 2.2 soil. Points show the estimated $\mathrm{LMC}_{50} \mathrm{~s}$ in $\mathrm{mg} / \mathrm{L}$ and error bars show the $95 \%$ confidence intervals for water $\mathrm{LMC}_{50} \mathrm{~s}$ only. Predicted porewater $\mathrm{LMC}_{50} \mathrm{~S}$ are within the confidence limits of water $\mathrm{LMC}_{50}$ s. See Table 1, Supporting Information for all values with corresponding confidence intervals 
Table 3 Toxicity- $\mathrm{K}_{\mathrm{d}}$ for the sorption of imidacloprid and modelled porewater $\mathrm{LC}_{50}$ values (in $\mathrm{mg} / \mathrm{L}$ ) for its toxicity to Folsomia candida in four different soils

\begin{tabular}{lllllll}
\hline Soil & $\begin{array}{l}\text { OC content } \\
(\%)\end{array}$ & $\begin{array}{l}\text { Toxicity- } K_{\mathrm{d}}(\mathrm{L} / \\
\mathrm{kg})\end{array}$ & $\begin{array}{l}\mathrm{LC}_{50}(\mathrm{mg} / \mathrm{kg} \\
\mathrm{dry} \text { soil })\end{array}$ & $\begin{array}{l}\mathrm{LC}_{50}(\mathrm{mg} / \\
\mathrm{L})\end{array}$ & $\begin{array}{l}\mathrm{EC}_{50}(\mathrm{mg} / \mathrm{kg} \\
\mathrm{dry} \text { soil })\end{array}$ & $\begin{array}{l}\mathrm{EC}_{50}(\mathrm{mg} / \\
\mathrm{L})\end{array}$ \\
\hline LUFA 2.2 & 2.32 & 0.053 & 0.31 & 5.85 & 0.14 & 2.64 \\
OECD 5 & 3.82 & 0.088 & 0.98 & 11.1 & 0.63 & 7.16 \\
OECD 10 & 6.29 & 0.145 & 1.63 & 11.2 & 2.07 & 14.3 \\
Grassland & 7.29 & 0.168 & 0.73 & 4.35 & 1.04 & 6.19 \\
\hline
\end{tabular}

$\% O C=$ organic carbon content (estimated by dividing OM\% with 1.73 )

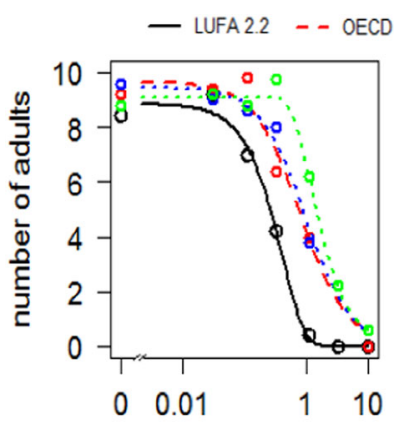

Concentration $(\mathrm{mg} / \mathrm{kg})$

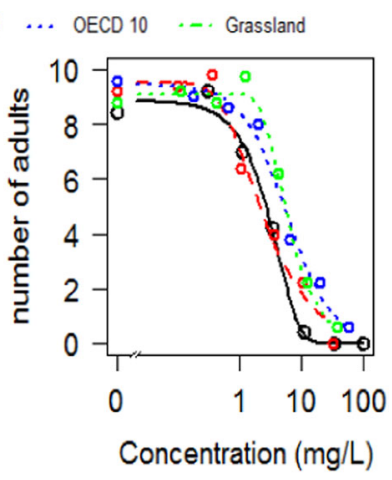

Concentration $(\mathrm{mg} / \mathrm{L})$
Fig. 4 Dose response relationships for the toxicity of imidacloprid to Folsomia candida in four different soils. Left: dose-response curves for the effects on survival based on concentrations of imidacloprid in $\mathrm{mg} / \mathrm{kg}$ dry soil. Right: dose-response curves based on recalculated imidacloprid concentrations in pore water. Decreased variability can be seen in the curves estimated in $\mathrm{mg} / \mathrm{L}$

(Toxicity- $K_{\mathrm{oc}}$ ) of $2.3 \mathrm{~L} / \mathrm{kg}$ was estimated for imidacloprid in LUFA 2.2 soil.

Since the variability of imidacloprid $K_{\mathrm{d}} \mathrm{s}$ in different soils was greatly reduced after normalizing for OM content (Liu et al 2006), the Toxicity- $K_{\text {oc }}$ for imidacloprid obtained was then used to estimate Toxicity- $K_{\mathrm{d}} \mathrm{s}$ for imidacloprid in the other three test soils (Table 3 ). When these Toxicity- $K_{\mathrm{d}} \mathrm{s}$ were used to recalculate the $\mathrm{LC}_{50} \mathrm{~s} / \mathrm{EC}_{50} \mathrm{~s}$ in $\mathrm{mg} / \mathrm{kg}$ dry soil into modelled porewater $\left(\mathrm{PW}_{\mathrm{m}}\right) \mathrm{LC}_{50} \mathrm{~s} / \mathrm{EC}_{50} \mathrm{~s}$ in $\mathrm{mg} / \mathrm{L}$, the differences between the four test soils became substantially lower (Table 3). Factor differences of $5.2(\mathrm{mg} / \mathrm{kg}$ dry soil) and of $2.6(\mathrm{mg} / \mathrm{L})$ were calculated for $\mathrm{LC}_{50} \mathrm{~s}$, and of $15(\mathrm{mg} /$ $\mathrm{kg}$ dry soil) and $5.4(\mathrm{mg} / \mathrm{L})$ for $\mathrm{EC}_{50} \mathrm{~s}$. A graphical representation of the decrease in variation in $\mathrm{LC}_{50} \mathrm{~S}$ obtained after conversion to $\mathrm{mg} / \mathrm{L}$ can be seen in Fig. 4 .

\section{Discussion}

\section{Reliability of the toxicity-Kd}

In the present study, a toxicity- $K_{\mathrm{d}}$ based on the $\mathrm{LMC}_{50} \mathrm{~s}$ for the toxicity of imidacloprid to $F$. candida in soil and water was estimated (Table 2 ). The toxicity- $K_{\mathrm{d}}$ was considered to be reliable because the value estimated via different methods proved to be similar; (1) Toxicity- $K_{\mathrm{d}} \mathrm{s}$ estimated for exposure durations of $14(0.03 \mathrm{~L} / \mathrm{kg})$ and 33 days $(0.05 \mathrm{~L} /$ $\mathrm{kg}$ ) are similar, (2) the 33-day-Toxicity- $K_{\mathrm{d}}$ is similar to the Literature- $K_{\mathrm{d}}$ of $0.085 \mathrm{~L} / \mathrm{kg}$ estimated from the $K_{\text {ow }}$ of imidacloprid, and (3) the 33 -day-Toxicity- $K_{\mathrm{d}}$ is similar to the slope $(0.085 \mathrm{~L} / \mathrm{kg})$ of the water-porewater regression curve which also represents a toxicity distribution. Furthermore, the $\mathrm{LC}_{50}(0.31 \mathrm{mg} / \mathrm{kg}$ dry soil $)$ and $\mathrm{EC}_{50}$ $(0.14 \mathrm{mg} / \mathrm{kg}$ dry soil) obtained for LUFA 2.2 soil in the present study is consistent with the values $\left(\mathrm{LC}_{50}=0.47 \mathrm{mg} /\right.$ $\mathrm{kg} ; \mathrm{EC}_{50}=0.26 \mathrm{mg} / \mathrm{kg}$ dry soil) obtained by De Lima e Silva et al. (2017) and the ones $\left(\mathrm{LC}_{50}=0.44 \mathrm{mg} / \mathrm{kg} ; \mathrm{EC}_{50}\right.$ $=0.29 \mathrm{mg} / \mathrm{kg}$ dry soil) obtained by Van Gestel et al. (2017). Similarly, the $\mathrm{LC}_{50}(1.63 \mathrm{mg} / \mathrm{kg}$ dry soil $)$ found for OECD 10 soil is consistent with the value of $1.38 \mathrm{mg} / \mathrm{kg}$ dry soil reported by Reynolds (2008). This shows the reproducibility of the results from this study and hence, the validity of soil toxicity values used to estimate toxicity- $K_{\mathrm{d}}$. Even though the toxicity- $K_{\mathrm{d}}$ seems valid, the occurrence of discrepancies cannot be ruled out. For instance, the polarity of imidacloprid suggests that its sorption to soil may not only be governed by partitioning to organic matter but also by the interaction with clay minerals (Rutherford et al. 1992). Moreover, the toxicity- $K_{\mathrm{oc}}$ of $2.3 \mathrm{~L} / \mathrm{kg}$ estimated for imidacloprid in LUFA 2.2 soil does not agree with literature $K_{\text {oc }}$ values of 132-300 L/kg (Fossen 2006; Liu et al. 2006). This discrepancy could be due to the chemical-based method used to determine the literature $K_{\mathrm{oc}}$ values compared to the toxicity-based method employed in the present study. Additionally, LUFA 2.2 soil was not included in the range of soils used to derive the $K_{\mathrm{oc}}$ values reported in the literature.

\section{Predicting toxicity 1: comparing toxicity in soil, water and pore water}

The extent of absorption, distribution, metabolism, excretion and hence the consequent toxicity of a chemical, is highly dependent on the exposure route of the organism $(\mathrm{Fu}$ et al. 2013). Several studies have shown that pore water is the most important route of chemical exposure for in-soil dwelling organisms by correlating toxicity to porewater concentrations (Martikainen and Krogh 1999; Styrishave et al. 2010). For that reason, uptake via pore water and 
water was investigated in this study and an attempt was made to predict soil toxicity. After estimating the Toxicity$K_{\mathrm{d}}$ from $\mathrm{LMC}_{50} \mathrm{~s}$, we then proceeded to use this value to estimate a different toxicity endpoint $\left(\mathrm{LC}_{50} \mathrm{~s}\right)$. Interestingly, the modelled porewater $\left(\mathrm{PW}_{\mathrm{m}}\right) \mathrm{LC}_{50} \mathrm{~s}$ recalculated from the soil $\mathrm{LC}_{50} \mathrm{~s}$ of $4.35-11.2 \mathrm{mg} / \mathrm{L}$ only differed by a factor of $0.55-1.43$ from the value of $6.22(\mathrm{CI}=4.95-7.50) \mathrm{mg} / \mathrm{L}$ obtained upon exposure in water. Similarly, the recalculated $\mathrm{PW}_{\mathrm{m}} \mathrm{LC}_{50}$ for LUFA 2.2 soil $(5.85 \mathrm{mg} / \mathrm{L})$ corresponds to the value $(4.71 \mathrm{mg} / \mathrm{L})$ obtained upon exposure in pore water extracted from LUFA 2.2 soil $\left(\mathrm{PW}_{\mathrm{e}}\right)$ (Tables 2 and 3). Ronday et al. (1997) also found similar toxicity relationships for the exposure of $F$. candida to carbofuran in water and pore water (using recalculated porewater values).

These comparisons imply that the toxicity of a chemical in the soil is mainly dependent on its porewater concentration and can be obtained from water exposures. This led to the postulation of a new hypothesis referred to as the "porewater extrapolation concept", which states that the toxicity of a chemical in the soil to $F$. candida can be related to porewater toxicity using the Toxicity- $K_{\mathrm{d}}$, and this porewater toxicity is considered to be equal to the water toxicity (Figure S5, Supporting Information). Applying this concept to toxicity data obtained in the present study means that the toxicity in the four soils can be predicted by exposing animals in water. Considering that the obtained water toxicity is equal to porewater toxicity, this can then be converted to soil toxicity values using the toxicity- $K_{\mathrm{d}}$. Most importantly, in cases where toxicity data is required for different soils, obtaining a single water toxicity data and $K_{\mathrm{d}} \mathrm{S}$ for different soils should be recommended. In such cases, water exposure is clearly a valuable and precise technique to predict soil toxicity. The "porewater extrapolation concept" could potentially be an extension of the porewater hypothesis and further research on the verification of such toxicity relationships is urgently required. However, there are indications that the porewater hypothesis, and hence the porewater extrapolation concept, may not be valid for highly lipophilic chemicals $\left(\log \mathrm{K}_{\mathrm{ow}}>5\right)$ which are likely to be taken up via the oral route (Belfroid et al. 1996; Jager et al. 2003).

\section{Predicting toxicity 2: comparing toxicity in different soils}

The porewater hypothesis proposed by Van Gestel and Ma $(1988,1990)$ assumes that the concentration of the chemical in the pore water causing a certain level of biological effect should be similar for different soils, and independent of the OM content (or other properties) of the soils. The availability of $K_{\mathrm{d}}$ values therefore allows the extrapolation of toxicity data between different soils (van Gestel 1997). In the present study, after recalculating the soil $\mathrm{LC}_{50}$ values, similar porewater $\mathrm{LC}_{50} \mathrm{~s}$ were obtained for both OECD artificial soils (OECD $5=11.1 \mathrm{mg} / \mathrm{L}$, OECD $10=11.2 \mathrm{mg} /$ $\mathrm{L}$ ), and these values were about a factor of 2-2.5 higher than those for the two natural soils [LUFA $2.2=5.85 \mathrm{mg} / \mathrm{L}$, Grassland $=4.35 \mathrm{mg} / \mathrm{L}]$ (Table 3). However, the disparity between artificial and natural soils was not observed when the $\mathrm{EC}_{50}$ values were recalculated and this is probably due to imidacloprid acting specifically on adult survival rather than reproduction (De Lima e Silva et al. 2017). Martikainen and Krogh (1999) also found only slight deviations for recalculated water $\mathrm{LC}_{50} \mathrm{~s}$ for the toxicity of dimethoate to $F$. candida in different soils, and they attributed the deviations to differences in microbial activity. This conclusion cannot be made in the present study because neither microbial activity nor degradation rates were monitored. An earlier study, however, showed imidacloprid to be fairly stable in LUFA 2.2 soil, with estimated half-lives of $>125$ days (Van Gestel et al. 2017). The differences between the $\mathrm{LC}_{50}$ s for artificial and natural soils could be due to different types of organic matter (peat) and clay (kaolin clay) present in the OECD artificial soils compared to the natural soils. These artificial soils also contained $65 \%$ more clay than the natural soils and therefore sorption to clay could not be neglected. Large specific surface area and high cation exchange capacity (CEC) make clay particles excellent adsorbents especially for cationic chemicals (Bhattacharyya and Gupta 2008). This suggests that the higher clay content of the OECD soils could lead to higher sorption of polar organic compounds such as imidacloprid. This form of sorption is not accounted for by measuring OM content, and might explain for the differences in recalculated water $\mathrm{LC}_{50}$ values (Ronday et al. 1997). Despite having the highest OM content, the low clay content of Grassland soil could be a plausible explanation for its relatively higher soil toxicity. Surprisingly, Grassland soil also had the highest toxicity after recalculating to porewater $\mathrm{LC}_{50}$ values (Table 3 ). As reported by Natal-da-Luz et al. (2012), this higher toxicity may be attributed to the presence of (low concentrations of) Lead (34.9 mg/kg), Zinc (36.2 mg/kg) and polycyclic aromatic hydrocarbons $(1.33 \mathrm{mg} / \mathrm{kg})$ in the Grassland soil.

\section{Conclusion}

The present study examined the role of porewater exposure in mediating the toxicity of imidacloprid to the springtail $F$. candida. We showed that clay minerals, if present in relatively high amount, can potentially influence the bioavailability of imidacloprid in the soil. Based on the porewater tests, we conclude that porewater and water exposures can potentially predict soil toxicity. Comparison of different exposure media enabled the postulation of the "porewater extrapolation concept," which relates soil toxicity to 
porewater and water toxicity, respectively. This study also presents an easy estimation method for $K_{\mathrm{d}}$ values that are toxicity-relevant, and which proves to be useful in cases of financial, technical and resource limitations in chemical analysis. It is strongly advised to validate this method before application in practice.

Although the realism of exposing soil animals in water is not straightforward and visible, this study was able to show the relevance of this kind of exposure for not only predicting lethal effects in the soil but also estimating intrinsic toxicity of a chemical without the influence of soil sorption. We conclude that the porewater test developed in this study may be used to predict the toxicity of water soluble-organic chemicals in the soil, as well as to extrapolate toxicity data among different soils.

Acknowledgements We acknowledge the assistance of Claudia de Lima e Silva and Rudo A. Verweij in setting up experiments

\section{Compliance with ethical standards}

Conflict of interest The authors declare that they have no conflict of interest.

Ethical approval This article does not contain any studies with human participants or animals performed by any of the authors.

Open Access This article is distributed under the terms of the Creative Commons Attribution 4.0 International License (http://crea tivecommons.org/licenses/by/4.0/), which permits use, duplication, adaptation, distribution, and reproduction in any medium or format, as long as you give appropriate credit to the original author(s) and the source, provide a link to the Creative Commons license, and indicate if changes were made.

\section{References}

Ardestani MM, van Straalen NM, Van Gestel CAM (2014) The relationship between metal toxicity and biotic ligand binding affinities in aquatic and soil organisms: a review. Environ Pollut 195:133-147

Belfroid AC (1994) Toxicokinetics of hydrophobic chemicals in earthworms: validation of the equilibrium partitioning theory. $\mathrm{PhD}$ thesis, Utrecht University

Belfroid AC, Sijm DTHM, Van Gestel CAM (1996) Bioavailability and toxicokinetics of hydrophobic aromatic compounds in benthic and terrestrial invertebrates. Environ Rev 4:276-299. https://doi.org/10.2307/envirevi.4.4.276

Bhattacharyya KG, Gupta SS (2008) Adsorption of a few heavy metals on natural and modified kaolinite and montmorillonite: a review Adv Colloid Interface Sci 140:114-131. https://doi.org/10.1016/j. cis.2007.12.008

Bonmatin JM, Giorio C, Girolami V, Goulson D, Kreutzweiser DP, Krupke C, Liess M, Long E, Marzaro M, Mitchell EA, Noome DA, Simon-Delso N, Tapparo A (2015) Environmental fate and exposure; neonicotinoids and fipronil. Environ Sci Pollut Res 22:35-67. https://doi.org/10.1007/s11356-014-3332-7

Bradham KD, Dayton EA, Basta NT, Schroder J, Payton M, Lanno RP (2006) Effect of soil properties on lead bioavailability and toxicity to earthworms. Environ Toxicol Chem 25:769-775. https:// doi.org/10.1897/04-552R.1
Dean-Ross D (1983) Methods for the assessment of the toxicity of environmental chemicals to earthworms. Regul Toxicol Pharmacol 3:48-59. https://doi.org/10.1016/0273-2300(83)90049-1

Escher BI, Hermens JLM (2004) Internal exposure: linking bioavailability to effects. Environ Sci Technol 38:455A

Filser J, Wiegmann S, Schröder B (2014) Collembola in ecotoxicology-Any news or just boring routine? Appl Soil Ecol 83:193-199. https://doi.org/10.1016/j.apsoil.2013.07.007

Fossen M (2006) Environmental fate of imidacloprid. California Department of Pesticide Regulation. http://www.cdpr.ca.gov/ docs/emon/pubs/fatememo/Imidclprdfate2.pdf. Accessed 5 September 2016

Fountain MT, Hopkin SP (2005) Folsomia candida (collembola): a "Standard" soil arthropod Annu Rev Entomol 50:201-222. https://doi.org/10.1146/annurev.ento.50.071803.130331

Fu C, Liu T, Li L, Liu H, Chen D, Tang F (2013) The absorption, distribution, excretion and toxicity of mesoporous silica nanoparticles in mice following different exposure routes Biomaterials 34:2565-2575. https://doi.org/10.1016/j.biomaterials.2012.12.043

Houx NWH, Aben WJM (1993) Bioavailability of pollutants to soil organisms via the soil solution Sci Total Environ 134(Suppl 1):387-395. https://doi.org/10.1016/S0048-9697(05)80039-7

Houx NWH, Dekker A, Kammen-Polman AMM, Ronday R (1996) Acute toxicity test for terrestrial hazard assessment with exposure of Folsomia candida to pesticides in an aqueous medium Arch Environ Contam Toxicol 30:9-14. https://doi.org/10.1007/ BF00211323

Jager T, Fleuren RHLJ, Hogendoorn EA, De Korte G (2003) Elucidating the routes of exposure for organic chemicals in the earthworm, Eisenia andrei (Oligochaeta). Environ Sci Technol 37:3399-3404. https://doi.org/10.1021/es0340578

De Lima e Silva C, Brennan N, Commandeur D, Verweij RA, Van Gestel CAM (2017) Comparative toxicity of imidacloprid and thiacloprid to different species of soil invertebrates. Ecotoxicology 26(4):555-564. https://doi.org/10.1007/s10646-017-1790-7

Liu W, Zheng W, Ma Y, Liu KK (2006) Sorption and degradation of imidacloprid in soil and water $\mathrm{J}$ Environ Sci Health Part B 41:623-34. https://doi.org/10.1080/03601230600701775

Lock K, Janssen CR (2003) Comparative toxicity of a zinc salt, zinc powder and zinc oxide to Eisenia fetida, Enchytraeus albidus and Folsomia candida Chemosphere 53:851-856. https://doi.org/10. 1016/S0045-6535(03)00593-9

Martikainen EAT, Krogh PH (1999) Effects of soil organic matter content and temperature on toxicity of dimethoate to Folsomia fimetaria (Collembola: Isotomiidae) Environ Toxicol Chem 18:865-872. https://doi.org/10.1002/etc.5620180508

Natal-da-Luz T, Lee I, Verweij RA, Morais PV, Van Velzen MJM, Sousa JP, Van Gestel CAM (2012) Influence of earthworm activity on microbial communities related with the degradation of persistent pollutants Environ Toxicol Chem 31:794-803. https:// doi.org/10.1002/etc. 1738

OECD (2009) Guideline for testing of chemicals no. 232: collembolan reproduction test in soil. Organization for Economic Co-operation and Development, Paris, 10.1787/9789264076273-en

OECD (1984) Guideline for testing of chemicals no. 207: earthworm, acute toxicity tests. Organization for Economic Co-operation and Development, Paris

OECD (2004) Guideline for testing of chemicals no. 222: earthworm reproduction test (Eisenia fetida/Eisenia andrei). Organization for Economic Co-operation and Development, Paris

Reynolds W (2008) Imidacloprid insecticide treatments for Hemlock Woolly Adelgid, Adelges tsugae Annand (Hemiptera: Adelgidae), affect a non-target soil arthropod community surrounding Eastern Hemlock, Tsuga canadensis (L.) Carriere, University of Tennessee 
Ritz C, Streibig JC (2005) Bioassay analysis using R. J Stat Softw 12:1-22

Ronday R, Houx NWH (1996) Suitability of seven species of soilinhabiting invertebrates for testing toxicity of pesticides in soil pore water. Pedobiologia 40:106-112

Ronday R, Van Kammen-Polman AMM, Dekker A, Houx NWH, Leistra M (1997) Persistence and toxicological effects of pesticides in topsoil: Use of the equilibrium partitioning theory. Environ Toxicol Chem 16:601-607

RStudio Team (2016) RStudio: Integrated development for R. RStudio, Inc., Boston, MA. http://www.rstudio.com/.

Rutherford DW, Chiou CT, Kile DE (1992) Influence of soil organic matter composition on the partition of organic compounds Environ Sci Technol 26:336-340. https://doi.org/10.1021/ es00026a014

Styrishave B, Hartnik T, Christensen P, Andersen O, Jensen J (2010) Influence of soil type and organic matter content on the bioavailability, accumulation, and toxicity of $\alpha$-cypermethrin in the springtail Folsomia candida Environ Toxicol Chem 29:1084-1090. https://doi.org/10.1002/etc. 127

Van Gestel CAM (1997) Scientific basis for extrapolating results from soil ecotoxicity tests to field conditions and the use of bioassays. In: van Straalen NM, Løkke H (ed) Ecological risk assessment of contaminants in soil. Springer, Boston, MA, p 25-50. 10.1007/ 978-1-4615-6361-7_2
Van Gestel CAM (2012) Soil ecotoxicology: state of the art and future directions ZooKeys 176:275-296. https://doi.org/10.3897/ zookeys.176.2275

Van Gestel CAM, de Lima e Silva C, Lam T, Koekkoek JC, Lamoree MH, Verweij RA (2017) Multigeneration toxicity of imidacloprid and thiacloprid to Folsomia candida. Ecotoxicology 26:320-328

Van Gestel CAM, Ma WC (1990) An approach to quantitative structure-activity relationships (QSARS) in earthworm toxicity studies. Chemosphere 21:1023-1033

Van Gestel CAM, Ma WC (1988) Toxicity and bioaccumulation of chlorophenols in earthworms in relation to bioavailability in soil. Ecotoxicol Environ Saf 15:289-297

Van Gestel CAM, Weeks JM (2004) Recommendations of the 3rd International workshop on Earthworm Ecotoxicology, Aarhus, Denmark, August 2001. Ecotoxicol Environ Saf 57:100-105

Van Gestel CAM, Van Dis WA (1988) The influence of soil characteristics on the toxicity of four chemicals to the earthworm Eisenia fetida andrei (Oligochaeta). Biol Fertil Soils 6:262-265

Waalewijn-Kool PL, Klein K, Fornies RM, Van Gestel CAM (2014) Bioaccumulation and toxicity of silver nanoparticles and silver nitrate to the soil arthropod Folsomia candida Ecotoxicology 23:1629-1637. https://doi.org/10.1007/s10646-014-1302-y

Crouau Y, Cazes L (2003) What causes variability in the Folsomia candida reproduction test? Appl Soil Ecol 22:175-180 